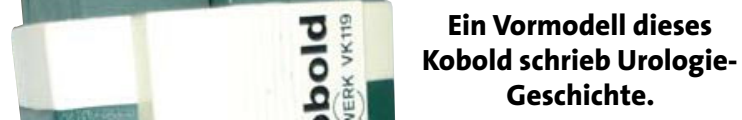

\section{Der Kobold am Werk}

\section{Wie eine urologische Doktorarbeit über Staubsauger-Verletzungen legendär wurde}

Nicht jeder Doktor der Medizin hat den Mut, Doktor ohne „Dr.“ zu werden. So entstehen Promotionsarbeiten von breit gefächerter Qualität. Von diesen wiederum schaffen es nur ganz wenige, zu einem populären

Klassiker zu werden, der schließlich (URO-)Kult- Status genießt: So die Promotion von Dr. Theimuras Michael Alschibaja: „Penisverletzungen bei Masturbation mit Staubsaugern“, eingereicht am 28.6.1978.

ie Firma Vorwerk ist ein traditionsreicher Hersteller von Staubsaugern und Reinigungsgeräten des Typs Kobold. Diese sind und waren für ihren universellen Einsatz berühmt: Da gab es zum Beispiel in grauer Vorzeit rohrartige Vorsätze mit einer Heizwendel um Haare zu trocknen. Auch Zubehör zur Tierpflege war erhältlich. Nur ein Vorsatzteil hatte die seriöse Firma niemals herausgebracht: die Onanie-Düse. Das jedoch hatte katastrophale Folgen, wie der urologische Kollege Alschibaja in seiner damaligen Doktorarbeit bei der Auswertung entsprechender Fälle beschrieb.

Ein kurzes Beispiel des Vorgangs: Uneregierten Penis in den Ansaugstutzen gesteckt. Durch Vibration und Sog erfolgreiche Erektion. Mit nun vergrößertem Penis das Lüfterrad erreicht. Verletzung. Klinik. Überlegung einer Ausrede wie „Hundebiss“.

Alschibaja beschreibt auch durchaus tragische Fälle, die dann freilich den Hintergrund für ein Kabarett bilden könnten: Ein junger Mann erleidet eine Verletzung wie oben beschrieben, sein Vater glaubt ihm nicht und probiert es selbst aus. Er muss daraufhin ebenfalls in die Klinik.

\section{Unvergessene Anamnesen}

Im Rahmen eigener Ambulanztätigkeit in den 1980er-Jahren las sich eine Anamnese so: Patient gab an, Auto gewaschen zu haben. Aus der weiten Badehose sei dabei der Penis herausgehangen, der Wind habe die Autotüre zugeschlagen und den Penis eingeklemmt. Ein weiterer Patient gab an, morgens nackt an seiner Hobelbank tätig gewesen zu sein. Aus Bequemlichkeit habe er seinen Penis auf diese gelegt. Der Hobel sei ihm ausgerutscht und dabei sei es zu der Verletzung gekommen (das sind Anamnesen, die man nie vergisst!). Die fällige Frage, ob da zufällig auch ein „Kobold“ mit dabei gewesen sei, wurde jeweils bejaht.

1985 wurde Alschibajas Promotionsarbeit regelrecht populär. Der „Chaos Computer Club“ (CCC) berichtete auf einer damaligen BTX-Seite (einer Art Internet-Vorläufer) vor dem Hintergrund der genannten Doktorarbeit unter dem Titel „Ona- nie macht krank“ über den Kobold. Der Slogan „N Nur saugen allein genügt nicht!" und "Saugen an unzugänglichen Stellen“ erschien damals ebenfalls auf dem Bildschirm. Für die Firma Vorwerk war es nur schwer vorstellbar, „dass deutsche Universitäten derart abwegige Themen vergeben“. Schließlich nahm sich 1986 der "Spiegel“ der Angelegenheit in einem mehrseitigen Artikel („Propeller am Penis“) an. In diesem berichtete er über ein dem CCC angedrohtes „Ordnungsgeld bis zu 500.000 DM“, alternativ eine „Ordnungshaft bis zu sechs Monaten“. Vor dem wissenschaftlichen Hintergrund der Promotion Alschibajas blieb es jedoch bei der Androhung.

Einige Jahre darauf (ab 2004) widmete sich Charlotte Roche, bekannt als Autorin des Buches „Feuchtgebiete“, der Doktorarbeit Alschibajas erneut und zitierte diese mit einigen Abstrichen im Rahmen einer Lesereihe, die sie unter anderem zusammen mit Christoph Maria Herbst unternahm. Diese „Penislesung“ fand an Lokalitäten mit durchaus passenden Namen wie „Wohnzimmertheater" oder "Schlachthof" statt. Die Frauen sollen gelacht haben, die Männer in sich zusammengesunken sein.

Als Moderatorin (2009/2010) der Fernseh-Talkshow „3 nach 9" bereitete Charlotte Roche das Thema erneut auf. Ihr Kommentar: „Ich denke, diese Männer wären bessere Liebhaber [...] sie sind Abenteurer". Und ein Diskussionsteilnehmer zieht die Bilanz: „Es verwundert nicht, dass die Staubsaugerindustrie sich verändert hat". Wie wahr: Eine spezielle Onanierdüse gibt es beim Kobold zwar noch immer nicht, dafür jedoch schon lange ein Schutzgitter beziehungsweise einen längeren Ansaugstutzen. So zeigt auch das Foto auf dieser Seite eine bereits verbesserte Variante des von Alschibaja gezeigten Typs.

Die Urologische Klinik und Poliklinik des Klinikums rechts der Isar der TU München, die Dr. Alschebaja den Doktortitel verliehen hatte, hat das dreißigjährige Jubiläum dieser „KultPromotion" offensichtlich ebenso übersehen wie die Redaktion von URO-NEWS. Somit überreichen wir Dr. Alschibaja nun erst im Nachhinein ein goldenes Staubsaugerlüfterrad nebst Urkunde als Anerkennung für seine Promotionsarbeit, auf die der seltene Fall zutrifft, es nach 30 Jahren unangefochten zum „URO-KULT“ gebracht zu haben. 